\section{At the Helm: A Laboratory Navigator}

\section{By Kathy Barker \\ Cold Spring Harbor Laboratory Press, $\$ 45.00,352$ pp, 2002}

\section{REVIEWED BY TARUN KAPOOR}

Laboratory of Chemistry and Cell Biology

Rockefeller University, New York, New York, USA

The lively, well-organized book, At the Helm: A Laboratory Navigator by Kathy Barker is a valuable resource for newly appointed principal investigators, who have to recruit, motivate and manage people, teach classes, carry out institutional responsibilities and compete for funding while doing ingenious researchthe only thing that they have been trained to do until now. Many principal investigators thus feel overwhelmed by the multitude of their new responsibilities. This book clearly lays out guidelines for those

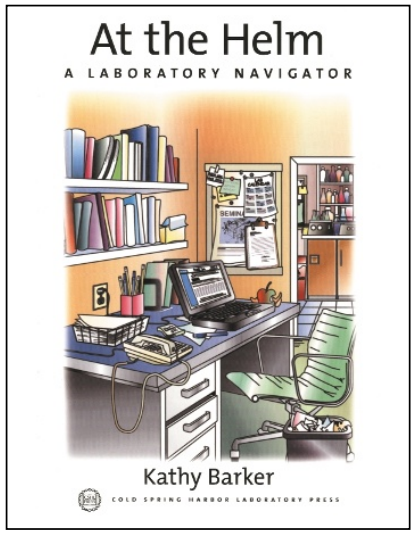

The book starts with a fair comparison of work as a scientist in the private sector versus the academic world for people who are weighing career options. For those choosing academic science, the book has tips on how to get the job, negotiate start-up packages and design lab space. She goes on from there to cover every imaginable aspect of setting up and running a lab. Among the topics covered in the book are hiring practices, time management, how to keep research central, lab organization, effective communication and how to be a leader.

The chapter "Choose Your People" was particularly telling. Advice about the hiring process is covered comprehensively. As the author explains the hiring protocol, she details how to review resumes, check references, set up and conduct an effective interview, evaluate the candidate and sell the job and what your lab has to offer. She cautions on prejudices that we may not be cognizant of and advises how we should work past first impressions. She also provides a useful primer on the differmaking the transition from their training and bench work as graduate students and postdoctoral fellows to running their own labs.

Written in a straightforward style, the book provides vital information needed to avoid common mistakes and get off to a good start. Barker interviews several new and seasoned lab leaders all around the United States, enlivening the text with their quotes and real life examples, while weaving in material from management sources. This presents a variety of opinions on any particular issue, so that there is something that everyone can identify with. By following the practical, easyto-use rules and advice, Barker suggests, new faculty can learn to head a lab with the highest levels of student motivation and creative research. They can also use its rule-based practices to become more productive and creative, write with greater ease, and socialize more successfully by learning about often-misunderstood aspects of academic and lab culture, including mentoring, she says. ent visa types we may encounter when hiring foreign researchers.

What surprised me most about the book was that it was not just a list of basic management mantras. Each chapter in At the Helm includes anonymous voices from many researchers around the country expressing candid opinions, anecdotes and ideas. These quotes include real solutions to some of the unusual problems that one might encounter as a new principal investigator. Clearly, many of these solutions have stood the test of time. In my first few months heading a lab, I came across circumstances that I thought were unique to my experience. It is comforting to know that there are many others who have been through similar situations, and can now look back and laugh!

As a new principal investigator, I think this book is necessary for everyone considering a scientific academic career to read before they start the trial and error of setting up their own labs. I believe experienced managers will also find some useful advice in it to help keep their labs running smoothly.

\section{Macroeconomics and Health: Investing in Health for Economic Development}

\author{
presented by Jeffrey D. Sachs \\ World Health Organization, Geneva \\ Available online: http://www3.who.- \\ int/whosis/cmh/cmh_report/e/report.cfm \\ $\$ 22.50,200$ pp, 2001 \\ REVIEWED BY ADRIAN J. IVINSON \\ Harvard Center for \\ Neurodegeneration and Repair \\ Harvard Medical School \\ Boston, Massachusetts, USA
}

The constitution of the World Health Organization (WHO) states, among other things, "The objective of the WHO shall be the attainment by all peoples of the highest possible level of health". It is always the simple statements that get us in trouble, and bearing in mind their definition of health- "a state of complete physical, mental and social well-being and not merely the absence of disease or infirmity"-this one seems to commit the organization, a priori, to failure. Can we ever contemplate "the highest possible level of health" for every living person? Perhaps not, but a recently published report presented by Jeffrey Sachs, Macroeconomics and Health: Investing in Health for Economic Development, takes us a step in the right direction.

In a 1988 acceptance speech, the newly elected Director-General of the WHO, Gro Harlem Brundtland, offered a somewhat more practical mandate for the leading organization dedicated to global health: to be "...the moral voice and the technical leader in improving health of the people of the world. Ready and able to give advice on the key issues that can unleash development and alleviate suffering. I see our purpose to be combating disease and ill-health-promoting sustainable and equitable health systems in all countries." Such a goal is a tad more practical maybe, but still quite a task.

Brundtland is key here. She came to the job from a background of public health and, thankfully, it shows. Public health, as the Oxford Medical Companion puts it, "...has its foundation not only in the biological and natural sciences, but also in the realm of 